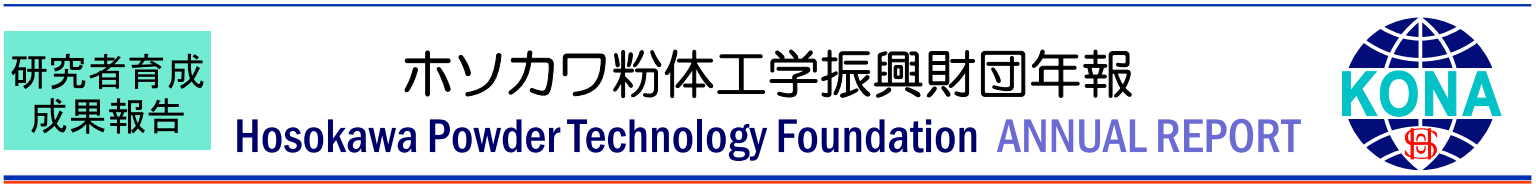

19510

\title{
微粒子のポーラス構造の精密制御とタンパク質吸着特性 \\ Controllable Synthesis of Porous Structured Fine Particles and Their Protein Adsorption Performance
}

\author{
援助対象者 Scholarship Student: Annie Mufyda RAHMATIKA \\ 広島大学大学院工学研究科 博士課程後期 3 年 \\ Graduate School of Engineering, Hiroshima University, PhD \\ Student (D3) \\ E-mail: annie-rahmatika@hiroshima-u.ac.jp
}

\author{
研究指導者Academic Leader：荻 崇 Takashi OGI \\ 教授, Professor \\ E-mail: ogit@hiroshima-u.ac.jp
}

\section{成 果 の 概 要}

\section{Background}

Effective protein adsorption has attracted attention for broad application in the biomedical applications, such as separation, purification, biosensor analysis, immobilization of protein and biomolecules delivery. To date, continuous improvement on adsorbent particles was developed by the utilization of various materials or modifying their physicochemical properties to increase the ability of adsorption, which is adjustable according to the required application. Thus, developing a novel advanced protein adsorbent that exhibited excellent adsorption performance, relatively lowcost and practical feasible is highly demanded.

Cellulose nanofiber (CNF) is a commonly used material in membrane chromatography and filtration for being chemically resistant and inexpensive, and possessing a high surface area, and good non-

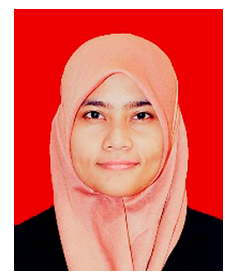

Annie Mufyda RAHMATIKA specific binding properties. However, to enhance affinity toward specific protein, cellulose must be modified to exhibit acidic functional groups via the oxidation of the hydroxyl group of cellulose. Saito et al. (Saito T. et al., 2007) had developed the system of oxidation of cellulose with 2,2,6,6tetramethylpiperidinyl-1-oxyl radical (TEMPO) with hypochlorite and bromide to convert the C6 primary hydroxyl group to a carboxylate group. TEMPO-oxidized cellulose nanofiber (TOCN) is a promising nanomaterial due to rich carboxyl that leads to a highly negative charge. The negative charge of TOCN in water causes electrostatic repulsion between TOCN, which leads to good dispersion in the wet state. In addition, with the carboxylate groups, TOCN is expected to be an effective adsorbent to specific protein considering their high content of carboxylate groups and negative charge. Even so, there is no research regarding utilization of TOCN, especially in the 
particle form as a protein adsorbent material because TOCN is easily aggregated in a drying process at elevated temperature which leads to a dense morphology (Zheng X. and Fu S. 2019). This dense morphology decreases the surface area and porosity, and significantly degrades the performance of adsorption capacity. Therefore, the preparation of TOCN particles that maintain their high surface area is challenging. Hence, in this study we focus on low TOCN loading on a $\mathrm{SiO}_{2}$ particles (TOCN@ macroporous $\mathrm{SiO}_{2}$ particles), and allowed elucidation of the lysozyme adsorption mechanism as a function of the host structure was observed by calculating the adsorption kinetics, thermodynamics and isotherm parameters.

\section{Experimental}

The preparation of TOCN@macroporous $\mathrm{SiO}_{2}$ particles was shown schematically in Fig. 1. Macroporous silica particles were produced using silica nanoparticles and 503-nm diameter polymethyl methacrylate (PMMA) as the template. An aqueous silica solution containing $12 \mathrm{wt} \%$ silica nanoparticles were added to the PMMA particles at a mass ratio of $1: 2$ (silica: PMMA). The silica concentration in the precursor was adjusted to as high as 2 wt. $\%$ by adding ultrapure water; the solution was then sonicated for 1 hour. The precursor was sprayed using an ultrasonic nebulizer with $\mathrm{N}_{2}(1 \mathrm{~mL} / \mathrm{min})$ as the carrier gas through a tubular furnace with four stacked temperature zones set to $150,350,500$, and $500^{\circ} \mathrm{C}$. The macroporous $\mathrm{SiO}_{2}$ particle was collected using a paper filter that was maintained at $150^{\circ} \mathrm{C}$ to prevent water condensation.

The $\zeta$-potential of macroporous silica then adjusted from negative to positive by stirring in 1 wt. \% poly(diallyldimethylammonium chloride) (PDDA) solution in water with ratio of silica/PDDA is $1 / 2$. After stirring for 30 minutes at room temperature and washing, the macroporous silica particles were poured in 0.1 wt. $\%$ TOCN aqueous solution with the mass ratio of $\mathrm{TOCN} / \mathrm{SiO}_{2}$ is 4 . The precursor was stirred for 2 hours at $50^{\circ} \mathrm{C}$ and

\section{Step 1: Preparation of Macroporous $\mathrm{SiO}_{2}$ Particles}

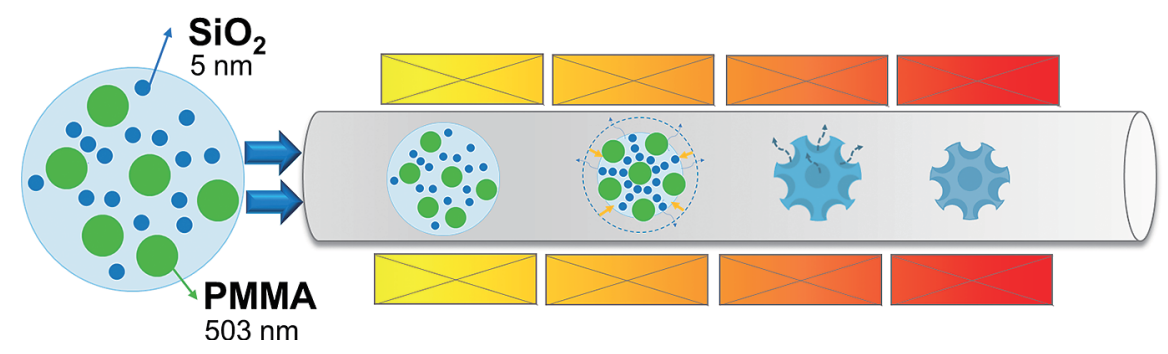

\section{Step 2: Synthesis of TOCN decorated Macroporous $\mathrm{SiO}_{2}$ Particles}

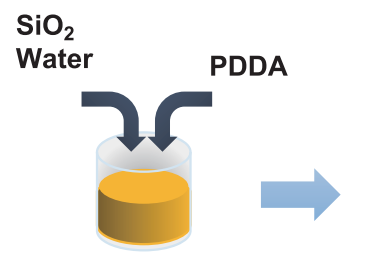

Stirring

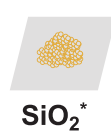

Rinsed \& Washing

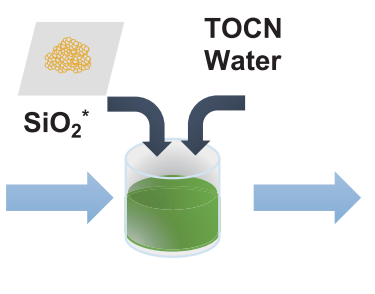

Stirring \& Heating

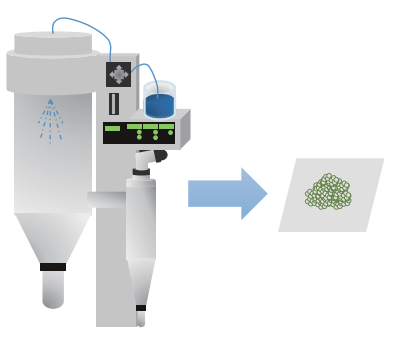

Spray Drying

Fig. 1 Schematic of the synthesis of TOCN@macroporous $\mathrm{SiO}_{2}$ particles. 
$800 \mathrm{rpm}$ then dried by spray drying at $180^{\circ} \mathrm{C}$. The performance of protein adsorption was investigated using lysozyme as the targeted model molecule. Aqueous lysozyme (with an isoelectric point of 10.5) solutions were prepared with a concentration of $0.4 \mathrm{mg} / \mathrm{mL}$ and a $\mathrm{pH}$ value of 7 was prepared using phosphate buffer.

\section{Result and Discussion}

In the development of adsorbent particles, the differences in structure (dense and macroporous structure) of $\mathrm{SiO}_{2}$ as supported particles is demonstrated the variation in TOCN loading deposition and the respective adsorption performance (Fig. 2).

The as-prepared adsorbent particles exhibited a high negative charge $(\sim-59 \mathrm{mV})$ and excellent protein adsorption ability $(>1,000 \mathrm{mg} / \mathrm{g})$ in $<5 \mathrm{~min}$. Furthermore, tuning the macropore size influenced the TOCN deposition either to the external surface or penetrating within the pores. The adsorption kinetics, thermodynamics, and isothermal parameters were studied to analyze the driving factors of protein adsorption. The results show that TOCNMacroporous $\mathrm{SiO}_{2}$ particles successfully satisfies the 3 criteria to be an advanced adsorbent: first, the surface is highly negatively-charged, which induces

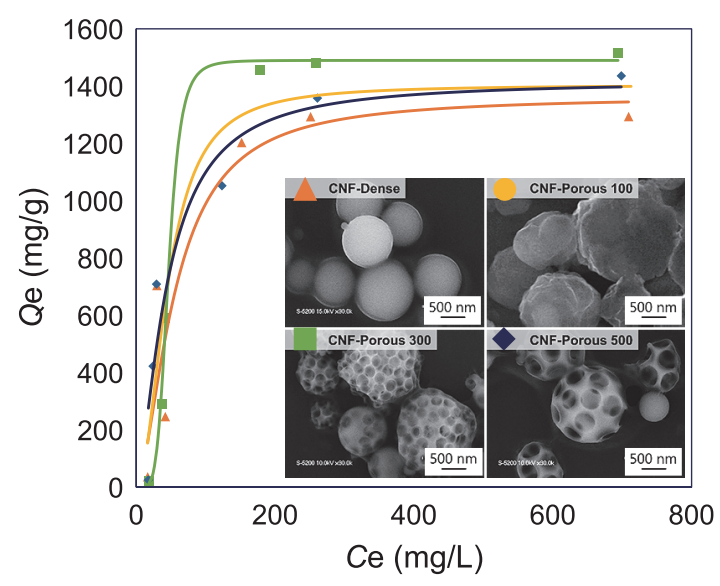

Fig. 2 Experimental data and the sips isotherm models of lysozyme adsorption onto CNF-silica particles. SEM images of prepared particles (inset). spontaneous effective adsorption (adsorption capacities $>1500 \mathrm{mg} / \mathrm{g},<5$ minutes) that occurred through electrostatic interaction and hydrogen bonding; second, a high surface area with $>50 \%$ of the total pore volume is mesoporous; and third, efficient ingress of macromolecules through open and continuous macroporous channels proven by the observed broad pore size distribution and a multistep diffusion process calculated from the MorinWeber models (Fig. 3). The adsorption process is confirmed to occur spontaneously at any temperature with a pseudo-second-order model describing the kinetic model, and TOCN deposition affecting the heterogeneity of the binding sites.

As a further development, the concentration of TOCN was variated. The morphologies of the TOCN@ $\mathrm{SiO}_{2}$ particles were compared with macroporous $\mathrm{SiO}_{2}$ and TOCN particle by SEM as shown in Fig. 4. From Fig. 4(a), macroporous silica was composed of sphere particles with $500 \mathrm{~nm}$ size of open porous. TOCN particle as shown in Fig. 4(b) consisted of an irregular sphere with a concave and wrinkled morphology due to rearranging of TOCN inside the droplet, then rapid shrinking in the drying process. While the TOCN@ $\mathrm{SiO}_{2}$ particle maintained their round shape because porous silica prevents TOCN from undergoing reconstruction during the evaporation process.TOCN@ $\mathrm{SiO}_{2}$ particles has a unique TOCN network structure on the macroporous particles (Fig. 4(c)) with a highlynegative zeta potential $(-62 \pm 2 \mathrm{mV})$ and relatively high surface area for cellulose based particle due to this unique structure. TOCN $@ \mathrm{SiO}_{2}$ particle shows broad pore size distribution (Fig. 4(d)) and higher intensity with the pore size peaks at 3, 4, and $16 \mathrm{~nm}$. Considering the dimension of lysozyme is $4.5 \times 3.0$ $x 3.0 \mathrm{~nm}^{3}$, the relevant pore size and the surface area become another factor to enhance the adsorption performance (Rouquerol F. et al., 1999).

The interesting point here is $\mathrm{TOCN}-\mathrm{SiO}_{2}$ particle had a similar functional group, similar zeta 

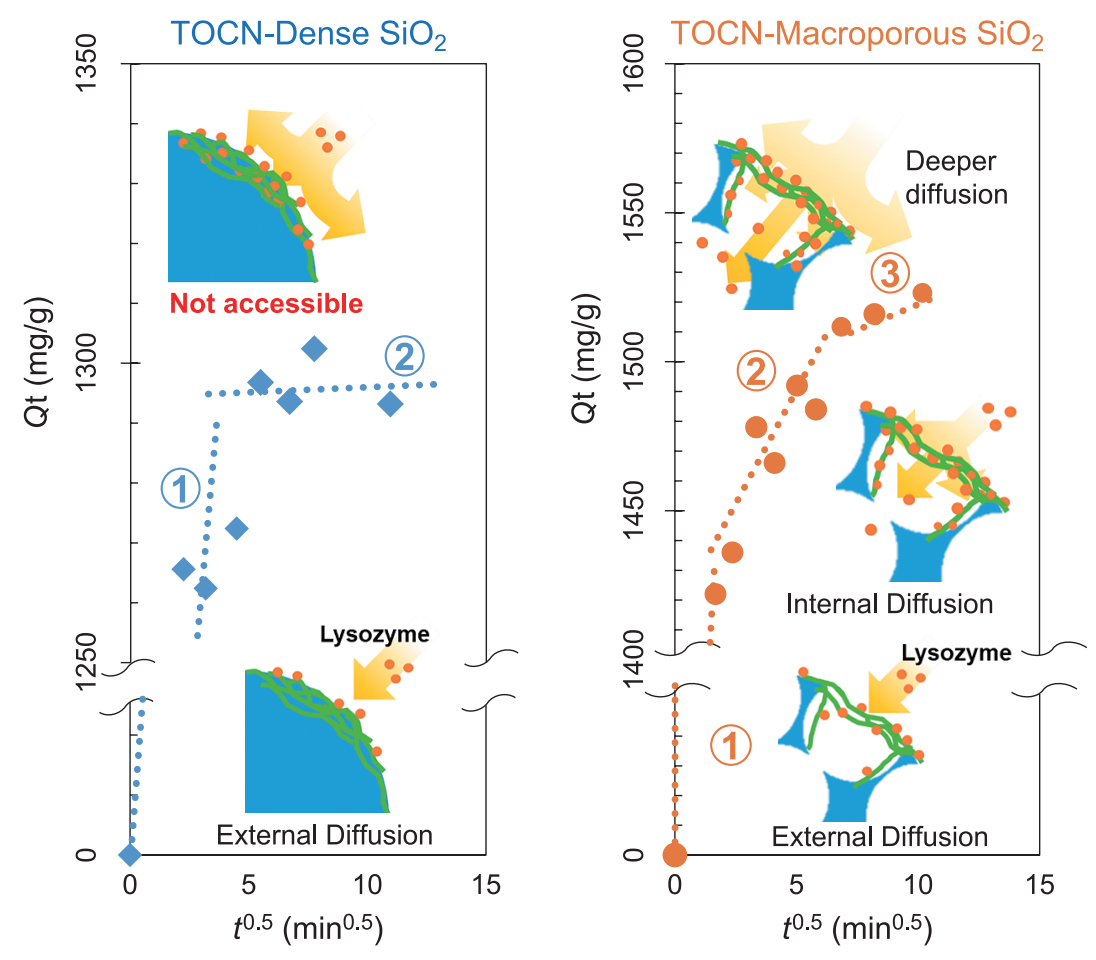

Fig. 3 Adsorption mechanism of lysozyme onto adsorbent particles.

potential, yet higher surface area than that of pure TOCN. TOCN particles have a highly negative charge due to the carboxylic group while TOCN@ $\mathrm{SiO}_{2}$ particles exhibited the most negative charges attributed to a higher concentration of, carboxyl and silanol groups as shown in Fig. 5(a).

Fig. 5(b) shows the lysozyme adsorption rates at the adsorbent concentration was $0.2 \mathrm{mg} / \mathrm{mL}$ of lysozyme solution.TOCN@ $\mathrm{SiO}_{2}$ particles have the highest adsorption capacities of lysozyme compared to TOCN and $\mathrm{SiO}_{2}$ particles. The adsorption of lysozyme by TOCN@ $\mathrm{SiO}_{2}$ particles exceeded 90\% of the initial amount of lysozyme in less than 5 minutes, with no significant increase with more adsorption time. Alternatively, the rates for TOCN particles were initially slow, continuing to slightly increase for the next 2 hours. The maximum amount of lysozyme adsorbed at equilibrium of TOCN particles were $1524 \mathrm{mg} / \mathrm{g}$, which is less than TOCN@SiO 2 particles (1873 mg/g). Interestingly, though TOCN@SiO $\mathrm{Sir}_{2}$ particles have lower amount
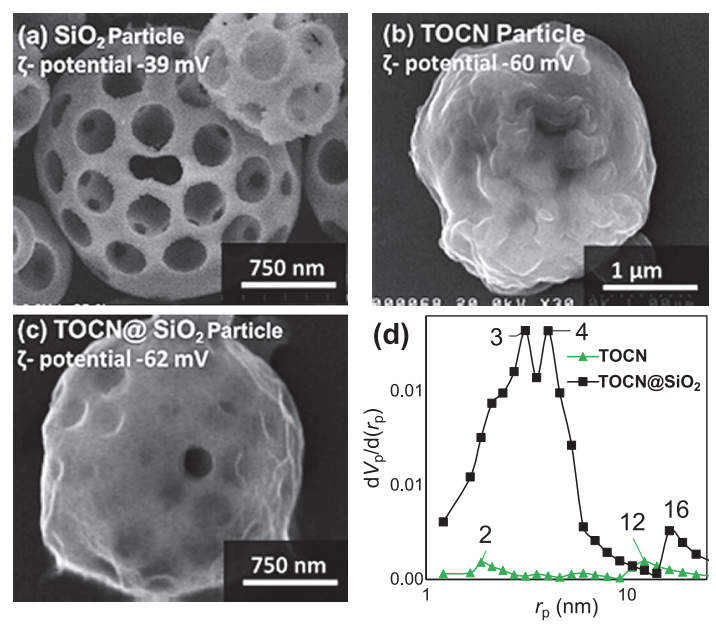

Fig. 4 SEM images of adsorbent (a) $\mathrm{SiO}_{2}$ particle; (b) TOCN particle; and (c) TOCN@ $\mathrm{SiO}_{2}$ particle; (d) Pore size distribution of prepared adsorbent.

of TOCN, its adsorption capacity is the highest. The better adsorption capacity of TOCN@ $\mathrm{SiO}_{2}$ particle is in exceptionally good agreement with existing $\zeta$-potential. In this case, the electrostatic interaction may play the most important role in enhancing the protein adsorption capacity of appropriate functional 
(a)

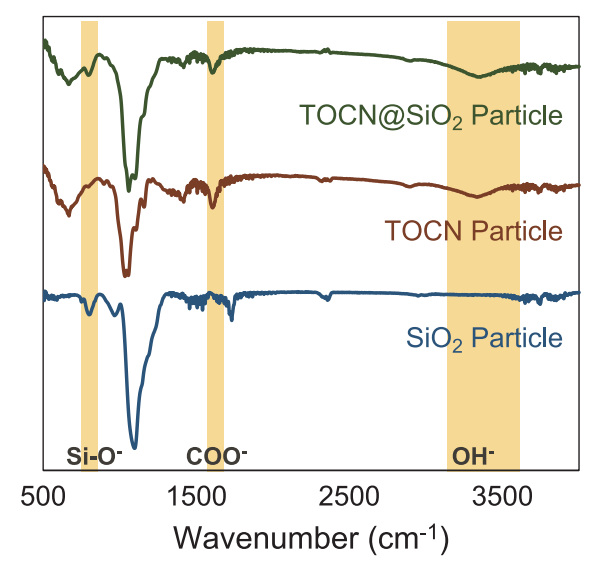

(b)

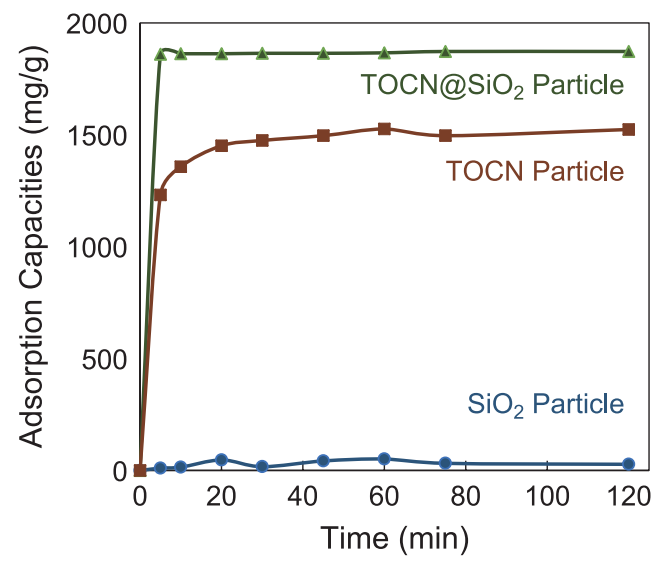

Fig. 5 (a) FTIR spectra of prepared adsorbent; (b) Adsorption rates for lysozyme of prepared adsorbent.

groups. Additionally, the larger pore size and board pore size distribution of TOCN@ $\mathrm{SiO}_{2}$ particle was beneficial for lysozyme adsorption as lysozyme could easily penetrate the TOCN network into free electrostatic site (Rahmatika A.M. et al., 2019).

\section{Conclusion}

A combination of TOCN and macroporous particles provide spontaneous adsorption through chemisorption. Moreover, the pore size corresponding to the length of TOCN possesses the complex structure that provides an abundance of accessible active sites that can adsorb macromolecules through multilayer adsorption and pore-filling mechanism. Moreover, we expect that the macroporous silica could be substituted with another material that is promising for wide application such as in protein adsorption, drug delivery, and biosensors.

\section{外部発表成果}

\section{論文発表}

1. Rahmatika A.M., Goi Y., Kitamura T., Morita Y.,

\section{参考文献}

Rahmatika A.M., Goi Y., Kitamura T., Widiyastuti W., Ogi T., TEMPO-oxidized cellulose nanofiber (TOCN) decorated macroporous silica particles: synthesis, characterization, and their application in protein adsorption, Materials Science and Engineering: C, 105 (2019) 110033. https://doi.org/10.1016/j.msec.2019.110033

Rouquerol F., Rouquerol J., Sing K., Adsorption by Powders and Porous Solids: Principles, Methodology and Applications, Academic Press, London, 1999, ISBN: 0125989202.

Saito T., Kimura S., Nishiyama Y., Isogai A., Cellulose nanofibers prepared by TEMPO-mediated oxidation of native cellulose, Biomacromolecules, 8 (2007) 2485-2491. https://doi.org/10.1021/bm0703970

Zheng X., Fu S., Reconstructing micro/nano hierarchical structures particle with nanocellulose for superhydrophobic coatings, Colloids and Surfaces A: Physicochemical and Engineering Aspects, 560 (2019) 171179. https://doi.org/10.1016/j.colsurfa.2018.10.005

Iskandar F., Ogi T., Silica-supported carboxylated cellulose nanofibers for effective lysozyme adsorption: effect of macropore size, Advanced Powder Technology, 31 (2020) 2932-2941. https://doi.org/10.1016/j.apt.2020.05.021 